\title{
Combined method for determining the optimal flow distribution plan for mining, urban electric vehicles and for charging stations
}

\author{
Viktor Kravets ${ }^{1}$, Kyryl Ziborov ${ }^{2}$, Kostiantyn Bas $^{1}$, and Serhii Fedoriachenko ${ }^{2 *}$ \\ ${ }^{1}$ Dnipro University of Technology, Department of Automotive Economy, 19 Yavornytskoho, \\ 49005 Dnipro, Ukraine \\ ${ }^{2}$ Dnipro University of Technology, Department of Machinery Design Fundamentals, 19 Yavornytskoho, \\ 49005 Dnipro, Ukraine
}

\begin{abstract}
The increase in the share of electric transport in mining and municipal enterprises in the short term may lead to changes in the structure of the transport fleet of enterprises and can affect the technology of work, in particular, surface mining operations. Changes in technology relate to the need for charging batteries, as well as the appropriate economic and technological planning. Having implemented the combinatorial representation and using the chain diagrams, a new method has been developed for determining the optimal plan of the vehicles flow distribution at the charging station of industrial enterprises, which provides the greatest enterprise profit. The developed mathematical model of vehicle flow at the charging station is compiled taking into account the objective constraints related to the cyclicality of the station loading capacity. The optimal plan for the vehicles flow distribution at the charging station is, based on geometric representations, as the greatest distance from the beginning of the reference to the plane (hyperplane), which passes through the vertex of the polyhedron of the area of admissible solutions and is oriented by the gradient of the target function (enterprise profit). The task becomes urgent in the light of the electrification of industrial transport and the improvement of batteries for them.
\end{abstract}

\section{Introduction}

The share of mineral deposits open mining reaches $85 \%$, and therefore this method facilitates the use of powerful and high-performance equipment, which provides low cost production. However, with the mine depth increase there are numbers of technological difficulties in providing the required level of extraction, preparation of open stocks and rock mass transportation to the surface, as well as providing the rolling stock with the necessary fuel reserves. This is conditioned by the transport kind, that used for hauling at open pits. Up to this moment only automobile transport is the major transport system, satisfies the technological needs [1].

\footnotetext{
* Corresponding author: serg.fedoryachenko@gmail.com
} 
Tendency to the use dump trucks with greater payload and increased mine depth exacerbates the problem of supply and fuel consumption. As the parameters of transport communications are determined by the size of vehicles, and the development of deep horizons is characterized by compressed conditions. In parallel with this, the increase in the cost of liquid fuels leads to an increase in the cost of transporting the rock mass.

The perspective increase of vehicles energy efficiency is carried out by an evolutionary transition from mechanical systems, using an internal combustion engine to electricmechanical systems basing on electric motor. Over the past five years, car makers have improved storage systems, and, therefore, it is likely that electric car dumps can appear in the next ten years. Therefore, improvement of the technological situation can be initiated by new kind of vehicles.

There definitely will be transition period and its duration can be predicted. Its characteristics flown from the presence and needs in maintenance both conventional and electric, including hybrid ones. In the cyclic maintenance process of the three types (conventional, hybrid, electric) at the charging station, there is a series of new tasks that require a comprehensive solution, based on fundamental results.

Proceeding from the development prospects and hypothetical presence in the park of mining enterprises different types of transport at the transition period, authors will try to create a mathematical apparatus for determining the optimal plan for the vehicles distribution with structural transformations of the production capacity at the charging station, including labor resources, consumables, equipment and corresponding adjustment of its mathematical model.

These trends and prospects for rechargeable electric vehicles can reduce greenhouse gas emissions if they are powered by renewable energy [2]. The barrier to widespread use on the market is a limited range per one charge. Although it is possible to find users who meet their needs by those technological developments that are currently available in the market [3]. However, the wider introduction of electric vehicles requires improved technology for energy storage or a significant expansion of the infrastructure of charging stations. It is also claimed by potential buyers of vehicles [4]. On the other hand, fast charging stations involve large investments [5], which require solving issues from the quantity, location of charging stations, and energy efficiency issues in the electric transport.

Therefore, in order to facilitate the electric transport dissemination, both industrial (including mining enterprises [10]) and utility, this paper proposes a new method for establishing the optimal location of charging stations based on a distribution plan for vehicles at a charging station.

\section{Probabilistic approach and description of transport flow}

Conventional vehicle is a mechanical system $[11,12]$, which includes an internal combustion engine and other units and aggregates that require diagnostics, recovery and consumable materials refuel. An electric vehicle is an electromechanical system that includes a motorwheel, batteries, and associated equipment that requires diagnostics, recovery and recharging $[13,14,15]$. Hybrid vehicles, being a combination of the first two - conventional and electric, require refueling and charging. The process of vehicles flow maintenance considered to be cyclical and random [16]. The appearance of a vehicle at a charging station of an enterprise is considered to be random event that has a discrete distribution law.

Table 1. Distribution law.

\begin{tabular}{|c|c|c|c|}
\hline \multirow{2}{*}{ Probability } & \multicolumn{3}{|c|}{ Vehicles } \\
\cline { 2 - 4 } & $D$ & $G$ & $E$ \\
\hline$P$ & $P_{1}$ & $P_{2}$ & $P_{3}$ \\
\hline
\end{tabular}


In Table 1 variable $P_{1}$ is the probability of a conventional vehicle with an internal combustion engine (accidental event $D$ ); $P_{2}$ is the probability of a hybrid vehicle (random event $G$ ); $P_{3}$ is probability of electric transport (accidental event $E$ );

The production capacity of the charging station is limited by the daily stock of consumables, available equipment and labor resources [17].

Distribution of different consumables, types of performed operations by vehicle types are presented in the following matrix form:

Table 2. Distribution of different consumables.

\begin{tabular}{|c|c|c|c|c|}
\hline \multirow{2}{*}{ Consumables } & \multicolumn{3}{|c|}{ Vehicles } & \multirow{2}{*}{ Daily supply } \\
\cline { 2 - 4 } & $D$ & $G$ & $E$ & $b_{1}$ \\
\hline 1. & $a_{11}$ & $a_{12}$ & $a_{13}$ & $b_{2}$ \\
2. & $a_{21}$ & $a_{22}$ & $a_{23}$ & $b_{3}$ \\
3. & $a_{31}$ & $a_{32}$ & $a_{33}$ & \\
$\cdot$ & & & & $\cdot$ \\
$\cdot$ & $\cdot$ & $\cdot$ & $\cdot$ & $b_{\mathrm{m}}$ \\
$\cdot \dot{m}$ & $a_{\mathrm{m} 1}$ & $a_{\mathrm{m} 1}$ & $a_{\mathrm{m} 1}$ & \\
\hline
\end{tabular}

Here the rectangular matrix is $(m \times 3)$ distribution of consumables according to the types of service at the vehicle charging station will look like:

$$
A=\left\|\begin{array}{|ccc}
a_{11} & a_{12} & a_{13} \\
a_{21} & a_{22} & a_{23} \\
a_{31} & a_{32} & a_{33} \\
\ldots & \\
a_{m 1} & a_{m 2} & a_{m 3}
\end{array}\right\| .
$$

Here the rectangular matrix is $(m \times 3)$ distribution of consumables according to the types of service at the vehicle charging station will look like:

$$
B=\left\|\begin{array}{c}
b_{1} \\
b_{2} \\
b_{3} \\
\cdot \\
b_{m}
\end{array}\right\| \text {. }
$$

Table 3. The matrix of the labor resources distribution.

\begin{tabular}{|c|c|c|c|c|}
\hline \multirow{2}{*}{$\begin{array}{c}\text { Service } \\
\text { operations }\end{array}$} & \multicolumn{3}{|c|}{ Vehicles } & Daily stock of labor \\
\cline { 2 - 4 } resources
\end{tabular}


Here is a rectangular matrix is $(n \times 3)$ distribution of labor resources by performing operations on available equipment:

$$
T=\left\|\begin{array}{|ccc}
t_{11} & t_{12} & t_{13} \\
t_{21} & t_{22} & t_{23} \\
t_{31} & t_{32} & t_{33} \\
& \ldots & \\
t_{n 1} & t_{n 2} & t_{n 3}
\end{array}\right\| .
$$

Matrix-column of the limited capacity of the charging station for the operations performed:

$$
F=\left\|\begin{array}{l}
f_{1} \\
f_{2} \\
f_{3} \\
f_{n}
\end{array}\right\| .
$$

The vehicles service cost at the filling station is considered to be set and presented by the matrix-line:

Table 4. Cost of vehicles maintenance at the charging station.

\begin{tabular}{|l|l|c|c|}
\hline \multirow{2}{*}{ Cost } & \multicolumn{3}{|c|}{ Vehicles } \\
\cline { 2 - 4 } & $D$ & $G$ & $E$ \\
\hline$C$ & $C_{1}$ & $C_{2}$ & $C_{3}$ \\
\hline
\end{tabular}

or

$$
C^{t}=\left\|C_{1} C_{2} C_{3}\right\|
$$

There are many flow plans for vehicle maintenance at the charging station that meet objective restrictions:

Table 5. Transport service plan at the charging station.

\begin{tabular}{|c|c|c|c|}
\hline \multirow{2}{*}{$\begin{array}{c}\text { Plan (vehicles } \\
\text { amount) }\end{array}$} & \multicolumn{3}{|c|}{ Vehicles } \\
\cline { 2 - 4 } & $D$ & $G$ & $E$ \\
\hline$X$ & $x_{1}$ & $x_{2}$ & $x_{3}$ \\
\hline
\end{tabular}

or matrix-column:

$$
X=\left\|\begin{array}{l}
x_{1} \\
x_{2} \\
x_{3}
\end{array}\right\| .
$$

Obviously, the variables $x_{1}, x_{2}, x_{3}$ are integers on the physical content and satisfy the trivial conditions:

$$
x_{1} \geq 0, x_{2} \geq 0, \quad x_{3} \geq 0 . x_{3} \geq 0
$$


It is also obvious that

$$
x_{1}+x_{2}+x_{3} \leq x,
$$

where $x$ is the daily capacity of the vehicles at the charging station or the daily average quantity of vehicles serviced at the charging station.

The objective function is the profit of a vehicle charging station, which is determined in a matrix form:

$$
L=C^{t} \times X
$$

or in expanded form:

$$
L=\left\|C_{1} C_{2} C_{3}\right\|\left\|\begin{array}{l}
x_{1} \\
x_{2} \\
x_{3}
\end{array}\right\| .
$$

Thus, the task is to find among the plenty of plans that, which meets the constraint conditions, the optimal distribution of the flow of vehicles, and provides the largest profit of the charging station.

\section{Mathematical model of transport and flow distribution}

Mathematical model of given task is made up with:

- target function

$$
L=C^{t} \times X
$$

- boundary conditions, which describe random flow distribution

$$
X \leq \bar{x} P
$$

where

$$
P=\left\|\begin{array}{l}
P_{1} \\
P_{2} \\
P_{3}
\end{array}\right\| .
$$

Or in explicit view:

$$
x_{1} \leq \bar{x} P_{1}, x_{2} \leq \bar{x} P_{2}, x_{2} \leq \bar{x} P_{3}
$$

- the flow of vehicles is limited to the daily throughput capacity of the charging station:

$$
x_{1}+x_{2}+x_{3} \leq \bar{x} P_{1}+\bar{x} P_{2}+\bar{x} P_{3}
$$

or

$$
x_{1}+x_{2}+x_{3} \leq \bar{x}\left(P_{1}+P_{2}+P_{3}\right)
$$

And thus $P_{1}+P_{2}+P_{3}=1$ will be obtained the following $x_{1}+x_{2}+x_{3} \leq \bar{x}$ :

- conditions-restrictions due to the daily stock of consumables at the charging station:

$$
A X \leq B
$$


- conditions-restrictions due to the daily labor resources and the availability of equipment for works at the maintenance station:

$$
T X \leq F .
$$

Thus, the mathematical model of this problem includes $N$ inequalities, where:

$$
N=m+n+3+3+1,
$$

which determines the area of permissible plans for the distribution of vehicle traffic at the charging station.

Mathematical modeling of traffic flow distribution. The area of admissible plans for the distribution of traffic flows is established on the set of points in the three-dimensional space obtained as the intersection of three boundary planes taken from $N$ constraints in different combinations of combinations:

$$
C_{N}^{3}=\frac{N(N-1)(N-2)}{1 \cdot 2 \cdot 3}
$$

The boundary planes form the following $n$ is equations, $m$ is equations:

$$
\begin{aligned}
& T X=A \\
& A X=B ;
\end{aligned}
$$

three equations:

$$
X=0
$$

three equations:

$$
X=x \bar{P}
$$

and one equation:

$$
x_{1}+x_{2}+x_{3} \leq \bar{x}
$$

A set of different systems of three linear algebraic equations determined by the number of combinations $C_{N}^{3}$, is constructed using chain diagrams. Methods for solving systems of linear algebraic equations are thoroughly developed and include the Gauss method, JordanGauss, the matrix method, the Cramer formula, integration methods, and others.

Solutions for each of them $C_{N}^{3}$ are permanent systems of algebraic equations.

The set of these points, which satisfies the conditions of a mathematical model, determines the vertices of the polyhedron area of the admissible flux distribution plans.

Among many admissible traffic flow distribution plans there is the optimal plan that provides the major revenue for the charging station.

Optimal plan for distributing vehicle flow at the charging station. Using geometric representations when searching for the optimal solution, the gradient of the target function is introduced:

$$
\overline{\operatorname{grad}} L=c_{1} \overline{e_{1}}+c_{2} \overline{e_{2}}+c_{3} \overline{e_{3}},
$$

which would correspond to a single vector:

$$
{ }_{n}^{0}=\frac{\overline{\operatorname{grad}}}{|\overline{\operatorname{grad} L}|}
$$


or in expanded form

$$
\bar{n}^{0}=\frac{1}{\sqrt{c_{1}^{2}+c_{2}^{2}+c_{3}^{3}}}\left(c_{1} \overline{e_{1}}+c_{2} \overline{e_{2}}+c_{3} \overline{e_{3}}\right)
$$

where $\bar{e}_{i}(i=1,2,3)$ is Orta of the considered basis. Each $j$-th vertex of the polyhedron of the admissible plan area corresponds to the radius of the vector:

$$
\bar{r}_{j}=x_{1}^{j} \bar{e}_{1}+x_{2}^{j} \bar{e}_{2}+x_{3}^{j} \bar{e}_{3} .
$$

In a normal vector form, a set of planes passing through each vertex of a polyhedron is constructed and guided by a gradient of the objective function:

$$
\bar{n}^{0}\left(\bar{r}-\bar{r}_{j}\right)=0,
$$

where $\bar{r}$ is radius vector of a plane arbitrary point.

$$
\left|d_{j}\right|=\left|\bar{n}^{0}\left(0-\bar{r}_{j}\right)\right|
$$

or

$$
d_{j}=\bar{n}^{0} \times \bar{r}_{j} .
$$

The vertex of the polygon corresponding to the largest distance $d_{\max }$ is selected. This vertex determines the optimal plan for distributing vehicle flow at the charging station i.e.

$$
\bar{r}_{\text {opt }}=x_{1}^{o p t} \bar{e}_{1}+x_{2}^{o p t} \bar{e}_{2}+x_{3}^{o p t} e_{3} \text {. }
$$

Indeed

$$
d_{\max }=\frac{1}{\sqrt{c_{1}^{2}+c_{2}^{2}+c_{3}^{3}}}\left(c_{1} \bar{e}_{1}+c_{2} \bar{e}_{2}+c_{3} \bar{e}_{3}\right) \times x_{1}^{o p t} \bar{e}_{1}+x_{2}^{o p t} \bar{e}_{2}+x_{3}^{o p t} \bar{e}_{3}
$$

or

$$
d_{\max }=\frac{1}{\sqrt{c_{1}^{2}+c_{2}^{2}+c_{3}^{3}}}\left(c_{1} x_{1}^{o p t}+c_{2} x_{2}^{o p t}+c_{3} x_{3}^{o p t}\right)
$$

where

$$
L_{o p t}=c_{1} x_{1}^{o p t}+c_{2} x_{2}^{o p t}+c_{3} x_{3}^{o p t}
$$

Thus,

$$
L_{\text {onm }}=|\overline{\operatorname{grad}} L| d_{\max } .
$$

That is, the target function is $L$ and distances is $d$, which are equivalent quantities that are different in task and constant multiplier $|\overline{\operatorname{grad}} L|$.

Methodological example. A hypothetical charging station for the maintenance of conventional $(D)$, hybrid $(G)$, electric $(E)$ vehicles is considered.

Conventional vehicles. Schemes based on internal combustion engines require diagnostics, recovery and refueling. EV that include motor-wheel, batteries, and other related equipment also require diagnostics, recovery and recharging. Hybrid cars, being a combination of conventional and electric, are serviced in full and require refueling and charging. The maintenance process of the vehicles flow considered at the charging station as a cyclic. The production capacity of the charging station is objectively limited by the 
daily stock of supplies, available equipment and labor resources. Let the distribution of the production capacity of the hypothetical maintenance station of conventional, hybrid and electric vehicles be represented by a rectangular matrix of the form:

$$
A=\left|\begin{array}{lll}
2 & 4 & 5 \\
1 & 8 & 6 \\
7 & 4 & 5 \\
4 & 6 & 7
\end{array}\right|
$$

Daily production capacity of the station is characterized by a column matrix:

$$
B=\left|\begin{array}{l}
120 \\
280 \\
240 \\
360
\end{array}\right| \text {. }
$$

The maintenance cost of conventional, hybrid and electric vehicles at a charging station is represented by a matrix line:

$$
C^{t}=\|10 \quad 14 \quad 12\| .
$$

Mathematical model. A lot of plans for maintaining the vehicle flow at the charging station in the form of a matrix-column introduced below:

$$
X=\left\|\begin{array}{l}
x_{1} \\
x_{2} \\
x_{3}
\end{array}\right\| .
$$

Variables $x_{1}, x_{2}, x_{3}$ are integers on the physical content of the problem and satisfy the trivial conditions:

$$
x_{1} \geq 0, \quad x_{2} \geq 0, \quad x_{3} \geq 0 .
$$

The target function is the profit of the charging station:

$$
L=C^{t} \times X
$$

or

$$
L=\left\|\begin{array}{lll}
10 & 14 & 12
\end{array}\right\|\left\|\begin{array}{l}
x_{1} \\
x_{2} \\
x_{3}
\end{array}\right\| .
$$

The limited daily production capacity of the charging station is described by the condition:

$$
A X \leq B
$$

or

$$
\left|\begin{array}{lll}
2 & 4 & 5 \\
1 & 8 & 6 \\
7 & 4 & 5 \\
4 & 6 & 7
\end{array}\right|\left\|\begin{array}{l}
x_{1} \\
x_{2} \\
x_{3}
\end{array}\right\| \leq\left\|\begin{array}{c}
120 \\
280 \\
240 \\
360
\end{array}\right\| .
$$


Thus, the mathematical model of this problem includes seven inequalities, which determine the area of permissible plans for distributing the flow at the charging station.

Among the plenty of plans that meet the constraints, there is an optimal distribution of traffic flow that provides the major revenue of the charging station.

The solution method. The given problem is solved by known methods of mathematical programming (simplex method, Gomoros method). Here is a new algorithm for solving a given problem (combinatorial method), based on the multiple use of known methods for solving systems of linear algebraic equations (Gauss method, Gauss-Jordan method, matrix method, Cramer formula, iteration method, Seidel method, etc.).

The area of admissible plans for the arrangement of the flow is established on the set of points in the three-dimensional space $x_{1}, x_{2}, x_{3}$, obtained as the intersection of three boundary planes taken from seven boundary conditions in various combinations. The boundary planes are the following seven algebraic equations:

$$
\begin{aligned}
& \text { I. } 2 x_{1}+4 x_{2}+5 x_{3}=120 ; \\
& \text { II. } 1 x_{1}+8 x_{2}+6 x_{3}=280 \\
& \text { III. } 7 x_{1}+4 x_{2}+5 x_{3}=360 \text {; } \\
& \text { IV. } 4 x_{1}+6 x_{2}+7 x_{3}=360 \text {; } \\
& \text { V. } x_{1}=0 \\
& \text { VI. } x_{2}=0 \\
& \text { VII. } x_{3}=0 .
\end{aligned}
$$

With the help of chain diagrams (Fig. 1), the entire set of different systems (35) of algebraic equations is constructed, i.e.

Solutions of the algebraic equations systems determine the set of 35 points in a threedimensional space, each makes the necessary conditional affiliation of them to the vertices of the admissible plans polyhedron. Sufficient conditions are checked for the correspondence of these points with the remaining inequalities remaining from the original mathematical model [11]. The set of points that meet the necessary and sufficient conditions, determines the vertices of the polyhedron of the area of acceptable distribution plans and means of transport. The optimal distribution plan that provides the most revenue for the charging station is in one of the obtained vertices of the polyhedron, the choice of which is trivial.

The results of the calculations for the complex 35 variants are summarized in the Table 6. 

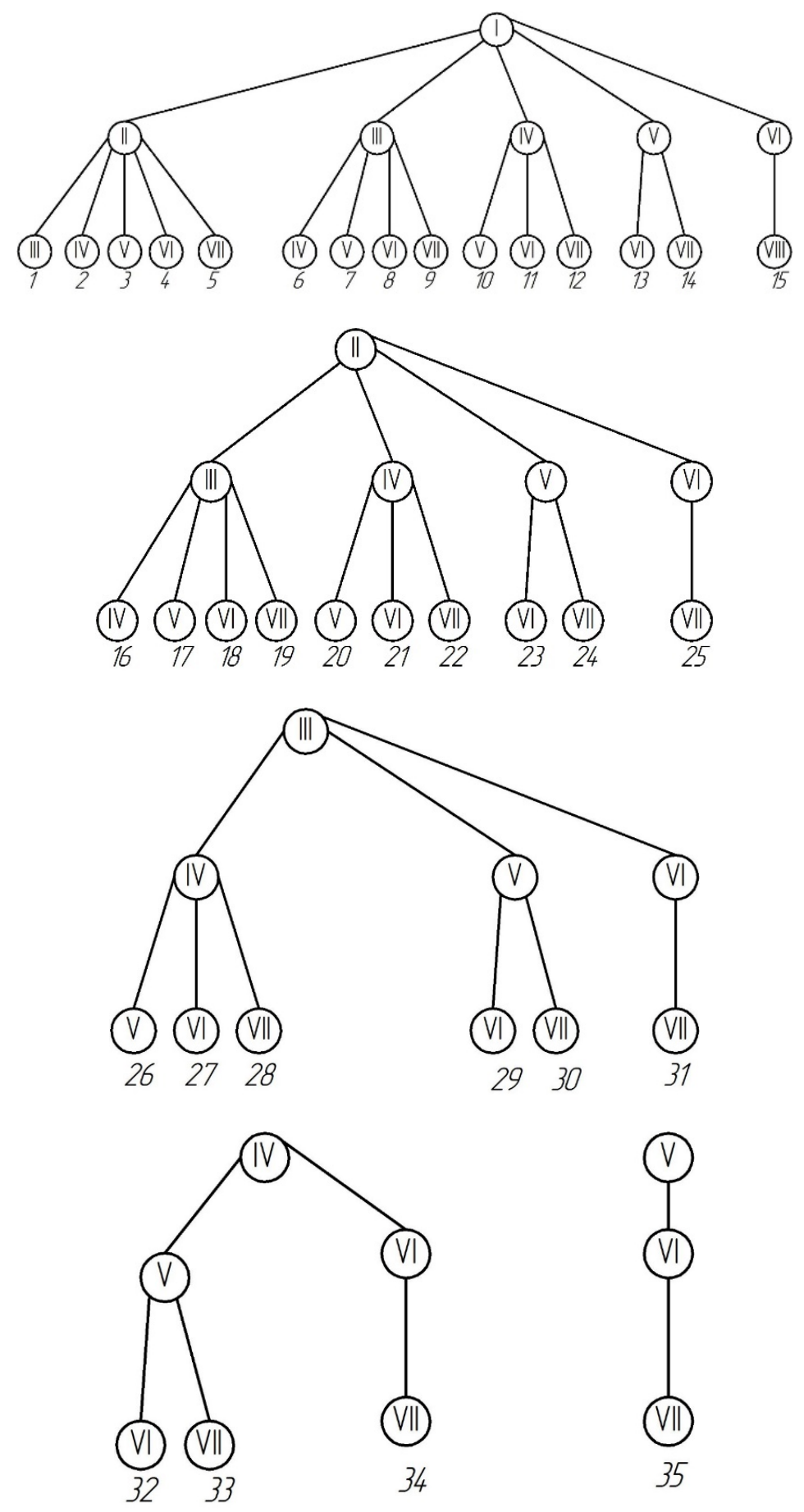

Fig. 1. Chain diagrams of different algebraic equations systems. 
Table 6. Results of performed calculations.

\begin{tabular}{|c|c|c|c|c|c|}
\hline \multirow{2}{*}{$\begin{array}{l}\text { Case } \\
\text { No. }\end{array}$} & \multicolumn{3}{|c|}{ Required condition } & \multirow{2}{*}{$\begin{array}{c}\text { Enforcement of } \\
\text { sufficient conditions }\end{array}$} & \multirow{2}{*}{$\begin{array}{l}\text { The value of the } \\
\text { target function }\end{array}$} \\
\hline & $X_{1}$ & $X_{2}$ & $X_{3}$ & & \\
\hline 1 & 24 & 53 & -28 & no & - \\
\hline 2 & 127 & 98 & -105 & no & - \\
\hline 3 & 0 & 42,5 & -10 & no & - \\
\hline 4 & -97 & 0 & 63 & no & - \\
\hline 5 & -13.3 & 36.8 & 0 & no & - \\
\hline 6 & 24 & 408 & -312 & no & - \\
\hline 7 & & no & & - & - \\
\hline 8 & 24 & 0 & 14.4 & yes & 412.8 \\
\hline 9 & 24 & 18 & 0 & yes & 492 \\
\hline 10 & 0 & 480 & -360 & no & - \\
\hline 11 & 160 & 0 & -40 & no & - \\
\hline 12 & 180 & -60 & 0 & no & - \\
\hline 13 & 0 & 0 & 24 & yes & 288 \\
\hline 14 & 0 & 30 & 0 & yes & 420 \\
\hline 15 & 60 & 0 & 0 & no & - \\
\hline 16 & -5.1 & -14.4 & 66.6 & no & - \\
\hline 17 & 0 & -0.4 & 50 & no & - \\
\hline 18 & 1.12 & 0 & 48.3 & no & - \\
\hline 19 & 15.4 & 33 & 0 & no & - \\
\hline 20 & 0 & -10 & 60 & no & - \\
\hline 21 & 11.8 & 0 & 44.6 & no & - \\
\hline 22 & 46.2 & 29.2 & 0 & no & - \\
\hline 23 & 0 & 0 & 46.6 & no & - \\
\hline 24 & 0 & 35 & 0 & no & - \\
\hline 25 & 280 & 0 & 0 & no & - \\
\hline 26 & 0 & 60 & 0 & no & - \\
\hline 27 & -4.1 & 0 & 53.8 & no & - \\
\hline 28 & 0 & 60 & 0 & no & - \\
\hline 29 & 0 & 0 & 48 & no & - \\
\hline 30 & 0 & 60 & 0 & no & - \\
\hline 31 & 34.4 & 0 & 0 & yes & 343 \\
\hline 32 & 0 & 0 & 51.5 & no & - \\
\hline 33 & 0 & 60 & 0 & no & - \\
\hline 34 & 90 & 0 & 0 & no & - \\
\hline 35 & 0 & 0 & 0 & yes & 0 \\
\hline
\end{tabular}

Thus, the vertices of polyhedron admissible plans area for the distribution of the transport flow at the charging station are the algebraic equations systems solution, corresponding to options No. 8, No. 9, No. 13, No. 14, No. 31, No. 35, where the target function is the profit of the enterprise. The results are the following values:

$$
L 9=492, L 13=288, L 14=420, L 31=342 \frac{6}{7}, L 35=0 \text {. }
$$


Here the greatest profit is $L 9=492$ and corresponds to the optimal plan for the distribution of transport flows:

$$
x_{1}=24, x_{2}=18, x_{3}=0,
$$

i.e. 24 is conventional vehicles with internal combustion engine; 18-hybrid vehicles; 0 -electric cars.

\section{Conclusions}

The increase of electric transport in mining and municipal enterprises in the short term may lead to changes in the structure of the transport fleet of enterprises and can affect the technology of work, in particular open mines. Changes in technology require charging batteries and appropriate planning of economic and technological process. The tendency to electrify the industrial transport of mining enterprises creates conditions for the development of a mathematical apparatus to determine the changes in the optimal plan for the traffic flows distribution and profits associated with structural transformations of production capacity, including labor resources, consumables, equipment.

Using combinatorial representation and chain diagrams, a new method was developed for determining the optimal vehicle flow distribution at the industrial power plant charging station, which provides the highest profit. This mathematical apparatus can be transferred to the conditions of the mining enterprise for the use of electrified industrial transport, which inevitably will be involved into technological process.

The dimension of the considered three-dimensional, cyclic, random flow consisting of conventional, hybrid and electric vehicles is not a limitation for the proposed combinatorial method. We trivially allow flow generalization of any dimension. The mathematical model of vehicle flow at the charging station is compiled taking into account objective constraints related to the cyclicality of the station capacity. The optimal plan for distributing the flow at the charging station is based on geometric representations as the greatest distance from the beginning of the reference to the plane (hyperplane) passing through the vertex of the polyhedron of the admissible solutions area and guided by the gradient of the target function (profit of the enterprise). The area of admissible plans is established using chain diagrams, and its search is reduced to the solution of the finite linear algebraic systems according to well-known algorithms. The developed algorithms can be implemented in the software environment for further implementation at the enterprises of the mining industry.

This work was conducted within the projects "Development a technical state forecast methodology for electrical-mechanical systems of electric and hybrid vehicles" (State registration No. 0118U003189). Special appreciation to professor Pivnyak G.G. for his support and guide.

\section{References}

1. Bass, K.M, Kuvayev, S.M., Plakhotnik, V.V. \& Krivda, V.V. (2014). Planar and spatial mathematical motion simulation of open pit mining vehicles, Naukovyi Visnyk Natsionalnoho Hirnychoho Universytetu, (3), 60-65.

2. Nordelöf, A., Messagie, M., Tillman, A.M., Söderman, M.L., Van J., Mierlo. (2014). Environmental impacts of hybrid, plug-in hybrid, and battery electric vehicles - what can we learn from life cycle assessment. International Journal Life Cycle Assessment, 19(11), 1866-1890.

3. Jakobsson, N., Gnann, T., Plötz, P., Sprei, F., \& Karlsson, S. (2016). Are multi-car households better suited for battery electric vehicles? - Driving patterns and economics in Sweden and Germany. Transportation Research Part C: Emerging Technologies, (65), 1-15. https://doi.org/10.1016/j.trc.2016.01.018 
4. Dütschke, E., Schneider, U., Sauer, A., Wietschel, M., Hoffmann, J., \& Domke, S. (2011). Roadmap zur Kundenakzeptanz - Zentrale Ergebnisse der sozialwissenschaftlichen Begleitforschung in den Modellregionen. Fraunhofer ISI, Federal Ministry of Transport, Building and Urban Development (Bundesministerium für Verkehr, Bau und Stadtentwicklung) (BMVBS), Berlin, Germany.

5. NPE. (2015). Ladeinfrastruktur für Elektrofahrzeuge in Deutschland. Statusbericht und Handlungsempfehlungen 2015. National Platform for Electromobility (NPE) - Working Group 3 - Charging infrastructure and grid integration.

6. Schroeder, A., \& Traber, T. (2012). The economics of fast charging infrastructure for electric vehicles. Energy Policy, (43), 136-144. https://doi.org/10.1016/j.enpol.2011.12.041

7. EC (European Commission. (2013). Proposal for a Directive of the European Parliament and the Council on the deployment of alternative fuels infrastructure. EC COM/2013/018 final. Brussels.

8. Gnann, T. (2015). Market Diffusion of Plug-in Electric Vehicles and Their Charging Infrastructure. Ph.D. Thesis. Germany: Karlsruhe Institute of Technology.

9. Gnann, T., Funke, S., Jakobsson, N., Plötz, P., Sprei, F., \& Bennehag, A. (2018). Fast charging infrastructure for electric vehicles: Today's situation and future needs. Transportation Research Part D: Transport and Environment, (62), 314-329. https://doi.org/10.1016/j.trd.2018.03.004

10. Taran, I.A. (2012). Interrelation of circular transfer ratio of double-split transmissions with regulation characteristic in case of planetary gear output. Naukovyi Visnyk Natsionalnoho hirnychoho universytetu, (3), 75-85.

11. Franchuk, V.P., Ziborov, K.A., Krivda, V.V., Fedoriachenko, S.O. (2018) Influence of thermophysical processes on the friction properties of wheel - rail pair in the contact area. Naukovyi Visnyk Natsionalnoho Hirnychoho Universytetu, (2), 46-52.

12. Ziborov, K.A., Protsiv, V.V., Fedoriachenko, S.O., Verner, I.V. (2016). On influence of design parameters of mining rail transport on safety indicators. Mechanics, Materials Science \& Engineering, 2(1), 63-70.

13. Ziborov, K., \& Fedoriachenko, S. (2014). The frictional work in pair wheel-rail in case of different structural scheme of mining rolling stock. Progressive Technologies of Coal, Coalbed Methane, and Ores Mining, 517-521. https://doi.org/10.1201/b17547-87

14. Kyrychenko, Y., Samusia, V., \& Kyrychenko, V. (2012). Software development for the automatic control system of deep-water hydrohoist. Geomechanical Processes During Underground Mining Proceedings of the School of Underground Mining, 81-86. https://doi.org/10.1201/b13157-14

15. Matsyuk, I., \& Shlyahov, E. (2015). The research of plane link complex structure mechanisms by vector algebra methods. Eastern-European Journal of Enterprise Technologies, 3(7), 34-38, https://doi.org/10.15587/1729-4061.2015.44236

16. Salov, V.O., \& Pismenkova, T.O. (2012), Formation of principles of new generation educational standards. Naukovyi Visnyk Natsionalnoho Hirnychoho Universytetu, (6), 130-136.

17. Semrad, K., Cernan, J., \& Draganova, K. (2016). Rolling Contact Fatigue Life Evaluation Using Weibull Distribution. Mechanics, Materials Science \& Engineering, 28-34. 